\title{
Exploring caesarean delivery in the second stage of labour at a tertiary care hospital: a retrospective study
}

\author{
Pravinkumar A. Jadav ${ }^{1 *}$, Palak M. Dabhi ${ }^{2}$, Dhruti A. Rathod ${ }^{1}$
}

\begin{abstract}
${ }^{1}$ Department of Obstetrics and Gynecology, B. J. Medical College, Ahmedabad, Gujarat, India ${ }^{2}$ Department of Obstetrics and Gynecology, General Hospital, Mansa, Gujarat and College of Physicians and Surgeons of Mumbai, Mumbai, Maharashtra, India
\end{abstract}

Received: 05 August 2021

Accepted: 06 September 2021

\author{
*Correspondence: \\ Dr. Pravinkumar A. Jadav, \\ E-mail: pravinjaddav@gmail.com
}

Copyright: (c) the author(s), publisher and licensee Medip Academy. This is an open-access article distributed under the terms of the Creative Commons Attribution Non-Commercial License, which permits unrestricted non-commercial use, distribution, and reproduction in any medium, provided the original work is properly cited.

\begin{abstract}
Background: Caesarean section (CS) performed in the second stage of labour has many implications for maternal and neonatal morbidity as well as for subsequent pregnancies. The objectives of this study were to determine the rates of $\mathrm{CS}$ at full dilatation, their indications, associated maternal and neonatal complications.

Methods: This retrospective study assessed all the women with a singleton fetus in cephalic presentation at term ( $\geq 37$ weeks) who underwent CS in the second stage of labor between 1 August 2019 and 31 March 2020 at a tertiary care hospital. Maternal demographics, labour and delivery details as well as neonatal outcomes were collected.

Results: During the study period, 2124 (36\%) babies were born by CS. Of these, $49(2.3 \%)$ were performed in the second stage of labour at $\geq 37$ weeks of gestation. The most common indication of CS was non-descent of head in 38 (77.55\%) of cases. The majority of women 38 (77.55\%) delivered by CS in the second stage of labor were primiparous. The $27(55.10 \%)$ women were in the age group of 20-25 years. Most common intraoperative complication was bloodstained urine in $20(40.81 \%)$ women. Overall transfusion rate was $18.36 \%$. Maximum number of babies born 44 $(89.79 \%)$ were having birth weight between $2.5-3.5 \mathrm{~kg}$. Out of 65 babies born, 17 (34.69\%) were admitted to neonatal intensive care unit.

Conclusions: Formulation of an institutional protocol and training and supervision of trainees to improve the skill of operative vaginal delivery and second stage cesarean is needed.
\end{abstract}

Keywords: CS, Second stage of labour, Maternal morbidity, Neonatal morbidity

\section{INTRODUCTION}

Caesarean section (CS) performed in the second stage of labour has many implications for maternal and neonatal morbidity as well as for subsequent pregnancies. The increasing CS rate is of significant international concern, with reported rates of $31.2 \%$ and $31.7 \%$ in the UK and USA, respectively. ${ }^{1,2}$ Incidence of second stage CS has increased from 0.9 to $2.2 \% .^{3}$ The Royal college of obstetricians and gynecologists (RCOG) reports that approximately $6 \%$ of CSs for singleton pregnancies occur at full dilatation. ${ }^{4}$ In half of these deliveries, there was no attempt at an instrumental delivery. ${ }^{4}$ This increasing trend of CS in second stage of labour is multifactorial, probably a combination of lack of training for junior staff in second stage decision making, lack of expertise in assisted vaginal delivery. ${ }^{5}$

CS in the second stage of labor is a technically difficult operation with distortion of pelvic anatomy and the deeply impacted fetal head in the maternal pelvis and the presence of thinned out edematous lower segment. CS at full dilatation, with or without attempt at operative vaginal delivery, is a more challenging surgical procedure than a first stage or non-laboring CS and carries a higher rate of maternal morbidity. ${ }^{6,7}$ 
The aims of this study were to determine the rates of CS at full dilatation, their indications, associated maternal and neonatal complications.

\section{METHODS}

This retrospective study assessed all CSs performed in the second stage of labor between 1 August 2019 and 31 March 2020 at tertiary care hospital. CS cases were identified through the operating theatre data log of obstetric cases. The electronic medical record, specifically the record of labour and operation reports, was reviewed for all CS cases over the study period. During the study period, total numbers of 2124 CSs were done, out of which 49 were performed in the second stage of labor. The total numbers of deliveries were 5759 .

Women with a singleton fetus in cephalic presentation at term ( $\geq 37$ weeks) who underwent caesarean delivery in the second stage of labour were included. Maternal demographics, labour and delivery details as well as neonatal outcomes were collected, analyzed and then presented in simple descriptive statistics using tables and charts.

\section{RESULTS}

During the index period, $2124(36 \%)$ women were delivered by CS. Of these, $49(2.3 \%)$ were in the second stage of labor $\geq 37$ weeks of gestation with a singleton fetus in cephalic presentation.

Table 1 outlines the maternal demographic characteristics. Out total CS s performed in the second stage of labor, there were $27(55.10 \%)$ women in the age group of 20-25 years and $17(34.70 \%)$ women in the age group of 26-30 years. $38(77.55 \%)$ of women were primigravida and 11 $(22.44 \%)$ of women were multigravida.

Table 1: Maternal demographic characteristics, $(n=49)$.

\begin{tabular}{|lcc|}
\begin{tabular}{|l} 
Demographic \\
characteristics
\end{tabular} & \multicolumn{1}{l|}{ Total } & Percentage $(\%)$ \\
\hline \multicolumn{2}{|l|}{ Distribution according to age } & (years) \\
\hline$<20$ & 3 & 6.12 \\
\hline $20-25$ & 27 & 55.10 \\
\hline $26-30$ & 17 & 34.70 \\
\hline$>30$ & 2 & 4.00 \\
\hline Distribution according to gravidity \\
\hline Primigravida & 38 & 77.55 \\
\hline Multigravida & 11 & 22.44 \\
\hline
\end{tabular}

Table 2: Type of labour, $(n=49)$.

\begin{tabular}{|lll|}
\hline Type of labour & Total & Percentage (\%) \\
\hline $\begin{array}{l}\text { Spontaneous } \\
\text { labour }\end{array}$ & 22 & 44.90 \\
\hline Induced labour & 27 & 55.10 \\
\hline
\end{tabular}

Table 2 shows that $22(44.90 \%)$ of women were with spontaneous labour and $27(55.10 \%)$ of women were with induced labour.

Table 3 shows 07 (14.28\%) women had anemia who all required blood transfusion, $10(20.40 \%)$ women had pregnancy induced hypertension, and 1 (2.00\%) had eclampsia. There were 3 mothers with previous CS who came in labour and trial of vaginal delivery was given after taking written informed consent.

Table 3: Associated maternal conditions, $(n=49)$.

\begin{tabular}{|lll|}
\hline Maternal condition & Total & Percentage (\%) \\
\hline Anemia & 07 & 14.28 \\
\hline $\begin{array}{l}\text { Pregnancy induced } \\
\text { hypertension }\end{array}$ & 10 & 20.40 \\
\hline Previous LSCS & 03 & 6.12 \\
\hline Eclampsia & 01 & 2.04 \\
\hline
\end{tabular}

Table 4 shows out of total $49 \mathrm{CS}$ s in the second stage labour, most common indication of CS was non-descent of head in $38(77.55 \%)$ of cases. 11 were performed for nondescend of fetal head with non-reassuring foetal heart rate, 14 were performed for non-descend of fetal head with thick meconium-stained liquor and 13 were performed for non-descend of fetal head with caput succedaneum. There were $11(22.44 \%)$ cases in which deep transverse arrest was the indication for CS $\mathrm{s}$ in the second stage of labour. Delivery of the deeply engaged head (found in 28\%) depended on the ease of the surgeon. Patwardhan technique was applied in $72 \%$ of these.

Table 4: Indications for second stage LSCS, $(n=49)$.

\begin{tabular}{|llll|}
\hline Variables & $\begin{array}{l}\text { Indications } \\
\text { I }\end{array}$ & $\begin{array}{l}\text { Ton descent of } \\
\text { head }\end{array}$ & $\begin{array}{l}\text { Percentage } \\
(\%)\end{array}$ \\
\hline IA & $\begin{array}{l}\text { With foetal } \\
\text { distress }\end{array}$ & 25 & 77.55 \\
\hline I & $\begin{array}{l}\text { Non reassuring } \\
\text { foetal heart rate }\end{array}$ & 11 & 22.44 \\
\hline Ii & $\begin{array}{l}\text { Thick } \\
\text { meconium- } \\
\text { stained liquor }\end{array}$ & 14 & 28.57 \\
\hline IB & $\begin{array}{l}\text { With caput } \\
\text { succedaneum }\end{array}$ & 13 & 26.53 \\
\hline II & $\begin{array}{l}\text { Deep transverse } \\
\text { arrest }\end{array}$ & 11 & 22.44 \\
\hline
\end{tabular}

Figure 1 illustrates the most common intraoperative complication was blood-stained urine in 20 (40.81\%) mothers which was due to advanced bladder during 2 nd stage of labour. Extension of uterine incision was seen in $13(26.53 \%)$ patients. Two $(4 \%)$ women had an atonic postpartum hemorrhage of more than $1000 \mathrm{ml}$, both of these women required blood transfusion, and the overall transfusion rate was $18.36 \%$. Anemia, atonic uterus and extension of uterine incision were causes for blood 
component transfusions. There was one maternal intensive care unit (ICU) admission due to eclampsia. Early post operative complications included post operative fever in 7 $(14.28 \%)$ patients and blood transfusion in one patient.

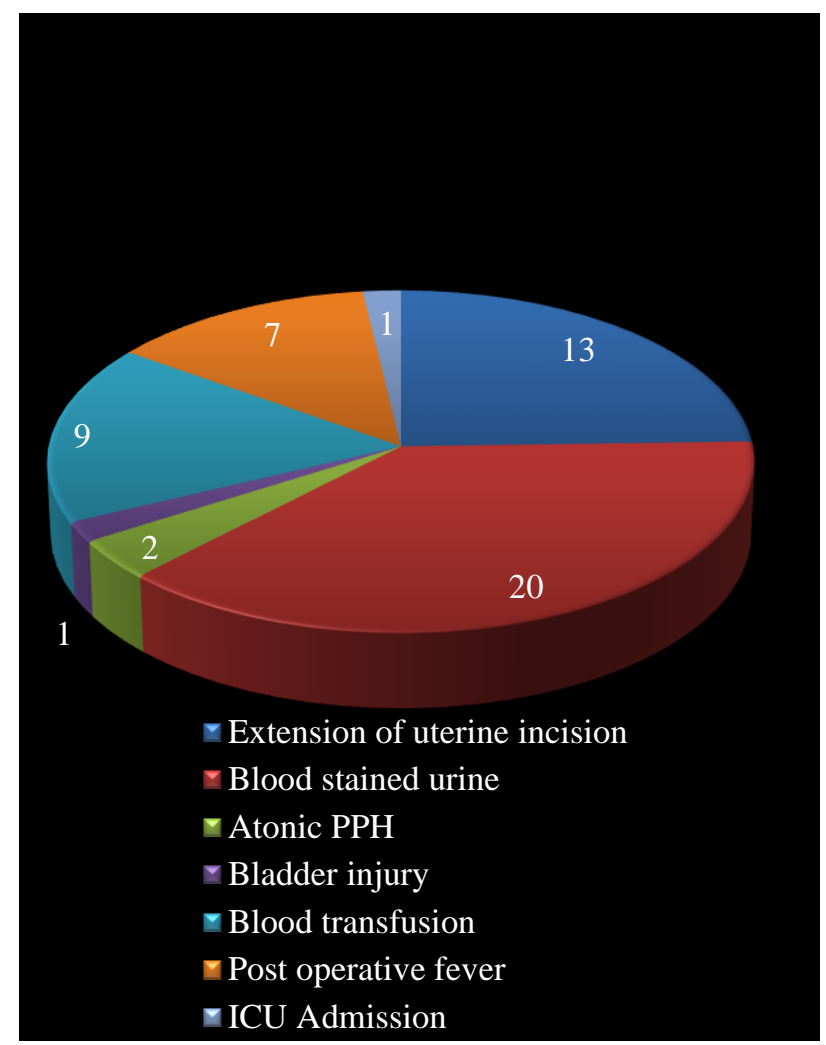

Figure 1: Maternal intra-operative and early postoperative complications.

Table 5: Baby birth weight distribution, $(n=49)$.

\begin{tabular}{|lll|}
\hline Birth weight (gm) & Total & Percentage (\%) \\
\hline$<2500$ & 2 & 4.08 \\
\hline $\mathbf{2 5 0 0 - 3 5 0 0}$ & 44 & 89.79 \\
\hline$>\mathbf{3 5 0 0}$ & 3 & 6.12 \\
\hline
\end{tabular}

Table 5 shows maximum numbers of babies were weighted in range of 2.5 to $3.5 \mathrm{~kg}$ in 44 cases $(89.79 \%)$. Out of these 24 babies had birth weight $\geq 3 \mathrm{~kg}$. Seventeen (34.69\%) babies were admitted to the NICU for management of respiratory distress, suspicious subgaleal hemorrhage and observation. There were no babies with confirmed subgaleal hematoma, stillbirths or neonatal deaths.

\section{DISCUSSION}

The international literature suggests that within a rising CS rate, there is an increasing trend to perform $\mathrm{CS}$ at full cervical dilatation. ${ }^{3,6,7}$ This trend appears to be multifactorial with an increasing perceived safety of CS coupled with a decrease in the experience of junior trainees with reluctance to attempt anticipated difficult instrumental deliveries.
In our study period, the overall CS rate was higher than international rates. ${ }^{3,5}$ This higher rate of CS might be because our hospital is a referral centre where high-risk patients from surrounding districts are referred, mostly for operative deliveries. However, our rates of in the second stage of labor are lower than other published cohorts. ${ }^{5}$ The lower rate may be explained by more women not reaching full dilatation due to an arrest in the first stage of labor or unsuccessful induction of labor.

Women delivered by CS at full dilation have a higher risk of obstetric hemorrhage, bladder injury, extended uterine tear leading to broad ligament hematoma, infection and longer hospital stay. ${ }^{8}$ The most common maternal operative complications seen in our study was bloodstained urine in $20(40.81 \%)$ women due to advanced bladder during second stage of labour. The $13(26.53 \%)$ had extension of uterine incision which is slightly higher compared to the other studies. ${ }^{9,10}$ This might be due to the fact that deep impacted fetal head with major caput and molding formation making the delivery of the fetal head challenging. There were febrile illnesses in 07 (14.28\%) women, ICU admission in $01(2 \%)$ women due to eclampsia and bladder injury in $01(2 \%)$ women. Overall blood transfusion rate was $18.36 \%$ mainly due to anemia, atonic PPH and extension of uterine incision. In a similar study done by Babre et al and Gupta et al blood transfusion rate was $8.2 \%$ and $8 \%$ respectively. ${ }^{9,11}$ Atonic postpartum hemorrhage was seen in $2(4 \%)$ cases, which is slightly less than in the previous studies. ${ }^{9,10}$ The use of prophylactic uterotonics in second stage caesarean could have contributed to this decreased number.

The most common indication for CS in the second stage in our study was non-descent of fetal head in 38 (77.55\%) patients (associated with either foetal distress or caput succedaneum). In a study done by Bhargava et al, most common indication of CS $(77.34 \%)$ in second stage was non-descent of fetal head, out of which $21.87 \%$ were with non-reassuring fetal heart rate and $24.21 \%$ were with meconium-stained liquor. ${ }^{12}$

In our study maximum number of women 27 (55.10\%) were in the age group of 20 to 25 years. In a similar study done by Gupta et al $46 \%$ women were in the age group of 21 to 30 years. ${ }^{11}$ In the present study maximum number $(77.55 \%)$ of women were primigravida. Similar results were seen in the study done by Babre et al in which $74 \%$ of patients were primigravida and in another study done by Unterscheider et al in which $76.5 \%$ cases were nulliparous. ${ }^{5,9}$

Babies born by cesarean section at full cervical dilatation are 1.5 times more likely to have perinatal asphyxia than those born by cesarean section during the first stage of labour. ${ }^{8}$ In our study maximum numbers of babies born (44) were having birth weight between $2.5-3.5 \mathrm{~kg}$. Out of 65 babies born, 17 (34.69\%) were admitted to neonatal intensive care unit. In a similar study done by Gupta et al $44 \%$ babies were admitted to neonatal intensive care unit. ${ }^{11}$ 
In another study done by Babre et al $54.1 \%$ of babies were admitted to neonatal intensive care unit. ${ }^{9}$

\section{CONCLUSION}

Cesarean section in full cervical dilation is an undesirable situation associated with maternal and fetal complications. When faced with difficult decisions relating to the management of arrest in the second stage of labour, practice is shaped by the obstetrician's skill, experience and preference. There are no randomized controlled trials guiding obstetricians when faced with the dilemma of determining whether to attempt an anticipated difficult instrumental vaginal delivery or immediate CS at full dilatation is the most appropriate mode of delivery. The main point of focus should be on strict monitoring of normal progression of labor, proper use of the partograph, pain relief measures and judicial use of oxytocin augmentation. Periodic audits regarding the rate of second stage cesarean section are required as well as formulation of an institutional protocol and training and supervision of trainees to improve the skill of operative vaginal delivery and second stage cesarean is needed.

Funding: No funding sources Conflict of interest: None declared

Ethical approval: The study was approved by the Institutional Ethics Committee

\section{REFERENCES}

1. NHS Digital. National Health Service Maternity Statistics-England 2019-2020. Available at: https://digital.nhs.uk/data-and-

information/publications/statistical/nhs-maternitystatistics/2019-20. Accessed on 4 August 2021.

2. Centre for Disease Control and Prevention (CDC)/National Centre for Health Statistics (US). Faststats: Births-Methods of Delivery. Available at: https://www.cdc.gov/nchs/fastats/delivery.htm. Accessed on 4 August 2021.

3. Vousden N, Cargill Z, Briley A, Tydeman G, Shennan $\mathrm{AH}$. Caesarean section at full dilatation: incidence, impact and current management. Obstet Gynecol. 2014;16(3):199-205.

4. Thomas J, Paranjothy S. Royal College of Obstetricians and Gynaecologist Clinical Effectiveness Support Unit. London: The national sentinel caesarean section audit. RCOG Press. 2001.

5. Unterscheider J, McMenamin M, Cullinane F. Rising rates of cesarean deliveries at full cervical dilatation: a concerning trend. Eur J Obstet Gynecol Repro Biol. 2011;157(2):141-4.

6. Stavrou EP, Ford JB, Shand AW. Epidemiology and trends for caesarean section births in New South Wales, Australia: a population-based study. BMC Pregnancy Childbirth. 2011;11:8.

7. Loudon JA, Groom KM, Hinkson L. Changing trends in operative delivery performed at full dilatation over a 10-year period. J Obstet Gynaecol. 2010;30(4):37075.

8. Allen VM, O'Connell CM, Baskett TF. Maternal and perinatal morbidity of caesarean delivery at full cervical dilatation compared with caesarean delivery in the first stage of labour. BJOG. 2005;112(7):98690.

9. Babre VM, Bendre KR, Niyogi G. Review of caesarean sections at full dilatation. Int $\mathrm{J}$ Reprod Contracept Obstet Gynecol. 2017;6(6):2491-3.

10. Baloch S, Khaskheli M, Khushk IA, Sheeba A. Frequency of second stage intervention and its outcome in relation with instrumental vaginal delivery versus caesarean section. J Ayub Med Coll Abbottabad. 2008;20(1):87-90.

11. Gupta K, Garg A. Fetomaternal outcome in caesarean section at full dilatation. Int $\mathrm{J}$ Reprod Contracept Obstet Gynecol. 2019;8:3098-101.

12. Bhargava S, Hooja N, Kala M, Mital P, Tulani K, Arora $\mathrm{S}$ et al. Caesarean delivery in the second stage of labour at a tertiarry care hospital. J Obstet Gynecol India. 2019;69(6):558-60.

Cite this article as: Jadav PA, Dabhi PM, Rathod DA. Exploring caesarean delivery in the second stage of labour at a tertiary care hospital: a retrospective study. Int J Reprod Contracept Obstet Gynecol 2021;10:3929-32. 